\title{
Evaluation of Dosing and Clinical Outcomes in Patients Undergoing Conversion of Insulin Glargine to Insulin Detemir
}

\author{
Ginelle A. Bryant, Pharm.D., Deanna L. McDanel, Pharm.D., Kathleen E. Horner, Pharm.D., \\ Karen B. Farris, Ph.D., and Erin N. Newkirk, Pharm.D.
}

Study Objectives. To evaluate the dose and frequency of insulin detemir for patients with diabetes mellitus undergoing conversion from insulin glargine to insulin detemir, and to assess glycemic control, weight gain, and risk of hypoglycemia after converting to insulin detemir.

Design. Retrospective medical record review.

Setting. Large academic medical center.

Patients. Thirty-one patients with type 1 (10 patients) or type 2 (21 patients) diabetes who were converted from insulin glargine to insulin detemir by usual practice between January 1, 2006, and March 3, 2007, after an Iowa Medicaid formulary switch.

Measurement and Main Results. Data were collected for 12 months after conversion from insulin glargine to insulin detemir. No significant change in mean basal insulin dose was noted in patients with type 1 diabetes at the end of 12 months (insulin detemir 31.1 units/day vs baseline insulin glargine 32.0 units/day, $\mathrm{p}=0.89$; insulin detemir 0.41 unit $/ \mathrm{kg} /$ day vs baseline insulin glargine $0.42 \mathrm{unit} / \mathrm{kg} / \mathrm{day}, \mathrm{p}=0.91$ ). In patients with type $2 \mathrm{dia}$ betes, however, the mean basal insulin dose was significantly higher with insulin detemir compared with baseline insulin glargine (74.2 vs 55.8 units/day, $\mathrm{p}=0.002 ; 0.68$ vs $0.48 \mathrm{unit} / \mathrm{kg} / \mathrm{day}, \mathrm{p}=0.001$ ) at the end of 12 months. Twice-daily administration was required in a higher proportion of patients receiving insulin detemir (15 patients [48\%]) at 12 months compared with insulin glargine (4 patients [13\%]) at baseline $(p=0.043)$. A significant change in hemoglobin $A_{1 c}$ was not observed in patients with type 1 diabetes $(9.7 \%$ with insulin detemir vs $9.3 \%$ with insulin glargine, $\mathrm{p}=0.41)$ or type 2 diabetes $(9.4 \%$ with insulin detemir vs $9.7 \%$ with insulin glargine at baseline, $\mathrm{p}=0.57$ ) despite the use of higher insulin detemir doses in patients with type 2 diabetes. No significant differences in weight or frequency of hypoglycemia were noted.

Conclusion. Treatment with insulin detemir appears to require more frequent administration and higher insulin doses compared with insulin glargine in patients with type 2 diabetes, with 33\% higher doses, on average, observed in this study. These findings suggest that a unit-for-unit conversion from insulin glargine to insulin detemir, as suggested by the manufacturer of insulin detemir, may not be adequate in patients with type 2 diabetes.

Key Words: glargine, detemir, basal insulin, long-acting insulin, insulin dose conversion.

(Pharmacotherapy 2013;33(1):56-62) 
Several landmark clinical trials have demonstrated that tight glycemic control reduces the incidence and delays the progression of long-term complications, particularly microvascular complications, associated with diabetes mellitus. ${ }^{1-4}$ Guidelines from the American Diabetes Association recommend targeting a hemoglobin $\mathrm{A}_{1 \mathrm{c}}(\mathrm{AlC})$ level of less than $7 \% .^{5}$ Long-acting insulin, with or without bolus insulin, is often required to achieve this tight glycemic control. There are two long-acting insulins available: insulin glargine (Lantus; Sanofi-Aventis, Bridgewater, NJ) and insulin detemir (Levemir; Novo Nordisk, Princeton, NJ). Both of these insulins have a long duration of action and have little variability in effect throughout the dosing interval (Table 1). However, insulin detemir has a dose-dependent onset and duration of action. Unlike insulin glargine, insulin detemir has a neutral $\mathrm{pH}$ and does not precipitate on injection. It instead exhibits its prolonged duration of action as a result of strong self-association and reversible binding to albumin. On May 1, 2006, Iowa Medicaid switched its preferred long-acting insulin from insulin glargine to insulin detemir, requiring the majority of insulin-dependent patients with Medicaid in Iowa to be switched to insulin detemir. The reason for the formulary change was unclear.

The manufacturer of insulin detemir suggests using a unit-for-unit dose conversion when switching patients from insulin glargine to insulin detemir. 8 Previous published studies, however, have evaluated the appropriateness of this dosage conversion primarily as a secondary end point or in trials of short duration. ${ }^{12-17}$ Thus, the primary objective of this study was to evaluate the dose and frequency of insulin detemir required when converting patients with type 1

From the Clinical Sciences Department, Drake University College of Pharmacy and Health Sciences, and Penn Avenue Internal Medicine, Des Moines, Iowa (G.A. Bryant); the University of Iowa Hospitals and Clinics and the University of Iowa College of Pharmacy, Iowa City, Iowa (D.L. McDanel and K.E. Horner); the University of Michigan College of Pharmacy, Ann Arbor, Michigan (K.B. Farris); and the Department of Pharmacy, Froedtert Hospital, Milwaukee, Wisconsin (E.N. Newkirk).

Presented as a poster at the annual meeting of the American College of Clinical Pharmacy, Louisville, Kentucky, October 21, 2008, and at the University HealthSystem Consortium Pharmacy Council Meeting Resident Poster Session, Las Vegas, Nevada, December 1, 2007.

For questions or comments, contact Ginelle Bryant, Pharm.D., BCPS, Drake University College of Pharmacy, 2507 University Avenue, Des Moines, IA 50311; e-mail: ginelle.schmidt@drake.edu. diabetes mellitus (T1DM) or type 2 diabetes mellitus (T2DM) from insulin glargine to insulin detemir. Secondary objectives were to assess glycemic control, weight gain, and the risk of hypoglycemia after conversion to insulin detemir.

\section{Methods}

This retrospective analysis evaluated 31 patients who underwent conversion from insulin glargine to insulin detemir by usual practice at a large academic medical center between January 1, 2006, and March 3, 2007. Patients were included if they were at least 18 years of age and had T1DM or T2DM and were excluded if they had gestational diabetes mellitus. Electronic medical records were used to identify patients, and data were collected during the 3 months before and 12 months after insulin conversion. This study was approved by the University of Iowa Institutional Review Board.

Primary outcome measures were mean basal insulin doses in both units/day and units/kg/day on the index date, defined as the date of conversion from insulin glargine to insulin detemir, and at 12 months; mean total insulin doses (basal plus bolus) in patients receiving more than one type of insulin; and frequency of basal insulin administration (once/day vs twice/day). Secondary outcomes were change in $\mathrm{AlC}$ and body weight observed during the 12 months after insulin conversion. In addition, the frequency of hypoglycemia, defined as the proportion of patients reporting at least one episode of hypoglycemia, was assessed during the 3 months before the index date while receiving insulin glargine and compared with the first 3 months after conversion to insulin detemir using any episode noted within the electronic medical records.

Statistical analysis was performed using the SPSS software, version 17 (Chicago, IL). Paired $t$ tests were used for continuous variables, including insulin dose, AlC, and weight. Discrete variables were analyzed with $\chi^{2}$ statistics. The analysis was performed using the last value carried forward for patients who did not complete the full 12 months of insulin detemir therapy. A planned subgroup analysis was performed to assess for differences between patients with T1DM and those with T2DM.

\section{Results}

A total of 31 patients, 10 patients with T1DM (32.3\%) and 21 patients with T2DM (67.7\%), 
Table 1. Comparison of Long-Acting Insulin Preparations

\begin{tabular}{llc}
\hline Property & \multicolumn{1}{c}{ Insulin Glargine ${ }^{6,7}$} & Insulin Detemir $^{7-10}$ \\
\hline Onset & $1.1 \mathrm{hrs}$ & $1.1-2$ hrs (dose dependent) \\
Duration & $10.8->24$ & $7.6->24$ hrs (dose dependent) \\
Peak & No significant peak & No significant peak \\
Insulin pH & 4.0 (acidic) & 7.4 (neutral) \\
Mechanism of prolonged & Low aqueous solubility & Strong self-association of the \\
duration of action & at physiologic pH results & molecules and reversible \\
& in precipitation on injection & binding to albumin \\
Recommended starting dose & 10 units once/day & $0.1-0.2$ units/kg once/day or \\
& & 10 units once or twice/day \\
Cost $^{11}$ & $\$ 118.99 / 10-\mathrm{ml}$ vial & $\$ 135.99 / 10-\mathrm{ml}$ vial
\end{tabular}

were included in the analysis; their baseline characteristics are shown in Table 2. The average age was 45 years, and patients generally had poorly controlled diabetes, with a mean baseline AlC of $9.6 \%$. The primary reason that patients were converted from insulin glargine to insulin detemir was insurance requirements, and the majority of patients were covered by Iowa Medicaid. Two patients had private insurance: one patient was converted to insulin detemir in an effort to reduce blood glucose variability and occurrence of hypoglycemia, whereas the other patient was converted due to the inability to mix insulin glargine with the patient's bolus insulin. (Although this was the reason documented in the patient's medical records, it should be noted that the manufacturer of insulin detemir does

Table 2. Baseline Characteristics of the 31 Study Patients $^{\mathrm{a}}$

\begin{tabular}{lc}
\hline Characteristic & Value \\
\hline Female sex & $19(61.3)$ \\
Diabetes mellitus type & $10(32.3)$ \\
Type 1 & $21(67.7)$ \\
Type 2 & $45 \pm 27$ \\
Age (yrs) & $35 \pm 11$ \\
Type 1 diabetes & $50 \pm 10$ \\
Type 2 diabetes & \\
Duration of diabetes & $2(6.5)$ \\
2-4 yrs & $9(29.0)$ \\
$5-10$ yrs & $20(64.5)$ \\
> 10 yrs & $9.58 \pm 2.45$ \\
Mean baseline AlC (\%) & $9.29 \pm 2.89$ \\
Type 1 diabetes & $9.72 \pm 2.27$ \\
Type 2 diabetes & $4(12.9)$ \\
At goal < 7\% & $100.6 \pm 30.6$ \\
Mean baseline weight (kg) & $76.1 \pm 17.9$ \\
Type 1 diabetes & $112.3 \pm 28.6$ \\
Type 2 diabetes & \\
Reason for conversion & $29(93.5)$ \\
Insurance & $2(6.5 \%)$ \\
Other
\end{tabular}

Data are no. (\%) of patients or mean \pm SD.

${ }^{a}$ Of the 31 patients, 10 had type 1 and 21 had type 2 diabetes. not recommend mixing insulin detemir with any other insulin preparations.)

Seven patients discontinued insulin detemir before completing 12 months of therapy. Four of these patients discontinued insulin detemir as a result of a lack of improvement in or worse blood glucose levels after a 4-7-month trial. Of the other three patients, one had an allergic reaction to insulin detemir, one was started on an insulin pump, and one discontinued insulin after subsequently developing hyperkalemia.

The majority (23 patients [74\%]) were converted from insulin glargine to insulin detemir on a unit-for-unit basis. Of the eight patients who were not converted on a unit-for-unit basis, five were placed on a higher insulin dose, potentially due to uncontrolled diabetes, and three had a decrease in insulin dose on conversion. Twelve months after switching, no significant change in mean insulin detemir dose was noted compared with baseline insulin glargine dose in patients with T1DM (31.1 vs 32.0 units/day, $\mathrm{p}=0.89$; 0.41 vs 0.42 unit $/ \mathrm{kg} / \mathrm{day}, \mathrm{p}=0.91$; Table 3 ). Conversely, patients with T2DM required a higher mean insulin detemir dose compared with the baseline insulin glargine dose $(74.2$ vs 55.8 units/day, $\mathrm{p}=0.002 ; 0.68$ vs 0.48 unit $/ \mathrm{kg} /$ day, $\mathrm{p}=0.001$ ). Insulin detemir doses were recorded at baseline (dose started on conversion) and at $1,3,6,9$, and 12 months after conversion (Table 4). At 1 month, patients with T2DM were on $11 \%$ higher mean basal insulin doses; at 3 months, 15\% higher doses; at 6 months, 27\% higher doses; at 9 months, 30\% higher doses; and by the end of 12 months, patients were maintained on 33\% higher insulin detemir doses compared with insulin glargine. Three patients with T2DM had bolus insulin added to their diabetes regimen at the end of the study period compared with baseline ( $67 \%$ vs $52 \%$, $\mathrm{p}=0.35$ ).

Lifestyle modifications and changes in other drug therapy were documented to assess whether 
Table 3. Mean Basal and Total Insulin Doses at Baseline and at Study Conclusion for Patients with Type 1 or Type 2 Diabetes Mellitus

\begin{tabular}{|c|c|c|c|c|c|}
\hline Primary End Point & $\begin{array}{l}\text { Type of } \\
\text { Diabetes } \\
\text { Mellitus }^{a}\end{array}$ & $\begin{array}{c}\text { Insulin } \\
\text { Glargine } \\
\text { (baseline) }\end{array}$ & $\begin{array}{l}\text { Insulin } \\
\text { Detemir } \\
\text { (12 mo) }\end{array}$ & $\begin{array}{l}\text { Change in } \\
\text { Insulin } \\
\text { Dose }\end{array}$ & $\mathrm{p}$ Value \\
\hline \multirow[t]{2}{*}{ Mean basal insulin dose (units/day) } & Type 1 & 32.0 & 31.1 & -0.9 & 0.89 \\
\hline & Type 2 & 55.8 & 74.2 & 18.4 & 0.002 \\
\hline \multirow[t]{2}{*}{ Mean basal insulin dose (units/kg/day) } & Type 1 & 0.42 & 0.41 & -0.01 & 0.91 \\
\hline & Type 2 & 0.48 & 0.68 & 0.20 & 0.001 \\
\hline \multirow[t]{2}{*}{ Mean total insulin dose ${ }^{b}$ (units/day) } & Type 1 & 53.9 & 54.7 & 0.80 & 0.92 \\
\hline & Type 2 & 84.0 & 106.8 & 22.8 & 0.001 \\
\hline \multirow[t]{2}{*}{ Mean total insulin dose ${ }^{\mathrm{b}}$ (units/kg/day) } & Type 1 & 0.69 & 0.69 & 0 & 0.95 \\
\hline & Type 2 & 0.75 & 0.97 & 0.22 & 0.002 \\
\hline
\end{tabular}

${ }^{\mathrm{a}}$ Of the 31 patients, 10 had type 1 and 21 had type 2 diabetes.

${ }^{\mathrm{b}}$ Total insulin dose includes both basal and bolus insulin doses.

Table 4. Mean Basal Insulin Doses over Time in Patients with Type 1 or Type 2 Diabetes Mellitus

\begin{tabular}{lcccccccc}
\hline & \multirow{2}{*}{$\begin{array}{l}\text { Type of } \\
\text { Diabetes }\end{array}$} & $\begin{array}{l}\text { Insulin } \\
\text { Glargine } \\
\text { Insulin Dose }\end{array}$ & \multicolumn{5}{c}{ Insulin Detemir } \\
\cline { 6 - 9 } & Mellitus & (baseline) & Baseline & 1 Months & 3 Months & 6 Months & 9 Months & 12 Months \\
\hline Mean basal insulin dose & Type 1 & 32.0 & 33.8 & 33.2 & 30.2 & 35.3 & 32.4 & 31.1 \\
(units/day) & Type 2 & 55.8 & 54.8 & 62.2 & 63.9 & 70.8 & 72.8 & 74.2 \\
Mean basal insulin dose & Type 1 & 0.42 & 0.43 & 0.42 & 0.39 & 0.45 & 0.42 & 0.41 \\
(units/kg/day) & Type 2 & 0.48 & 0.49 & 0.56 & 0.57 & 0.64 & 0.66 & 0.68 \\
\hline
\end{tabular}

Table 5. Lifestyle Changes or Changes in Other Antidiabetic Drugs in the 31 Study Patients

\begin{tabular}{lcc}
\hline $\begin{array}{l}\text { Type of Change in } \\
\text { Diabetes Regimen }\end{array}$ & $\begin{array}{c}\text { Insulin } \\
\text { Glargine } \\
\text { (baseline) }\end{array}$ & $\begin{array}{c}\text { Insulin } \\
\text { Detemir } \\
(12 \mathrm{mo})\end{array}$ \\
\hline $\begin{array}{l}\text { Lifestyle modifications } \\
\text { No. of concomitant oral } \\
\text { antidiabetic drugs }\end{array}$ & $12(38.7)$ & $13(41.9)$ \\
0 & $17(54.8)$ & $18(58.1)$ \\
1 & $7(22.6)$ & $10(32.3)$ \\
2 & $6(19.4)$ & $3(9.7)$ \\
3 & $1(3.2)$ & $0(0)$ \\
Patients taking & $14(45.2)$ & $13(41.9)$ \\
concomitant & & \\
oral drugs & & $7(22.6)$ \\
Insulin type & & $24(77.4)$ \\
Basal insulin only & $10(32.3)$ & \\
Basal + bolus insulin & $21(67.7)$ &
\end{tabular}

changes in these factors could account for any change in insulin doses or glycemic control observed (Table 5). A similar number of patients were found to be implementing lifestyle modifications at baseline and study completion, as were a similar number of patients taking oral drugs. Thus, these changes were thought to have minimal impact on glycemic control and on the increases in insulin detemir doses observed in this study.

Fifteen patients with T1DM or T2DM were administering insulin detemir twice/day at the
Table 6. Percentage of Patients Administering Basal Insulin Twice/Day ${ }^{\mathrm{a}}$

\begin{tabular}{|c|c|c|c|}
\hline Insulin Type & $\begin{array}{l}\text { atients with } \\
\text { Type } 1 \\
\text { Diabetes } \\
\text { Mellitus } \\
(\mathrm{n}=10)\end{array}$ & $\begin{array}{l}\text { atients with } \\
\text { Type } 2 \\
\text { Diabetes } \\
\text { Mellitus } \\
(n=21)\end{array}$ & $\begin{array}{l}\text { All Patients } \\
\quad(n=31)\end{array}$ \\
\hline $\begin{array}{l}\text { Insulin glargine } \\
\text { (baseline) }\end{array}$ & $0 \%$ & $19 \%$ & \\
\hline $\begin{array}{l}\text { Insulin detemir } \\
\text { (index date }{ }^{c} \text { ) }\end{array}$ & $40 \%$ & $33 \%$ & $35 \%$ \\
\hline $\begin{array}{l}\text { Insulin detemir } \\
(12 \mathrm{mo})\end{array}$ & $50 \%$ & $48 \%$ & $48 \%{ }^{b}$ \\
\hline \multicolumn{4}{|c|}{$\begin{array}{l}{ }^{a} \text { The frequency of dosing was twice/day except for one patient who } \\
\text { received insulin detemir } 3 \text { times/day at } 12 \text { mo. } \\
{ }^{b} \mathrm{p}=0.043 \text { for the percentage of patients receiving insulin glargine } \\
\text { at baseline compared with those receiving insulin detemir at } \\
12 \text { mo. } \\
12 \text { The index date was defined as the date of conversion from insulin } \\
\text { glargine to insulin detemir. }\end{array}$} \\
\hline
\end{tabular}

end of 12 months compared with four patients administering insulin glargine at baseline (48\% vs $13 \%, p=0.043$; Table 6 ). The percentages of patients receiving twice-daily basal insulin administration were similar at study completion in patients with T1DM and T2DM $(50 \%$ and $48 \%$, respectively). Seven (47\%) of the 15 patients who were taking twice-daily basal insulin at the end of the study period were automatically converted from once-daily to twice-daily administration on conversion to insulin detemir on the index date. This may have been due to 
physician knowledge of the potentially shorter duration of action, which has been demonstrated to be dose dependent in previous studies. ${ }^{10}$ The mean daily insulin detemir dose was 0.53 unit/ $\mathrm{kg}$ at the time that these seven patients were automatically converted from once-daily insulin glargine to twice-daily insulin detemir (insulin detemir dose on the index date).

A nonsignificant increase in $\mathrm{AlC}$ was observed in patients with T1DM from baseline to study completion ( $9.3 \%$ vs $9.7 \%, p=0.41)$, with no change in basal insulin dose in these patients. Despite the use of significantly higher insulin detemir doses in patients with T2DM, no significant change in AlC was observed from baseline to study completion $(9.7 \%$ vs $9.4 \%$, $\mathrm{p}=0.57$ ). In addition, with the conversion, a lower proportion of patients achieved a goal AlC of less than $7 \%$ as recommended by the American Diabetes Association at the end of the 12 months, although this was a nonsignificant difference ( $13 \%$ vs $4 \%, p=0.148$ ). Weight gain was not observed despite an increase in total insulin doses (mean change $-1.4 \mathrm{~kg}, \mathrm{p}=0.87$ ). Mean weight change was $-0.4 \mathrm{~kg}$ in patients with T1DM and $-1.82 \mathrm{~kg}$ in patients with T2DM from baseline to study completion. The number of patients experiencing at least one episode of hypoglycemia did not differ significantly between insulin glargine and insulin detemir (13 patients [41.9\%] vs 6 patients [19.4\%], $\mathrm{p}=0.054)$.

\section{Discussion}

In this study, treatment with insulin detemir required higher basal insulin doses compared with insulin glargine, with 33\% higher doses observed in patients with T2DM 12 months after conversion. Most of the patients in this study had uncontrolled diabetes, with an average AlC of $9.6 \%$ at baseline. Thus, it is not unexpected that the patients would require higher insulin doses to reach glycemic targets. However, contrary to what one would expect, the higher doses did not result in improved glycemic control. It could be argued that a clinically significant change in AlC was observed in patients with T2DM (although not statistically significant), but there was one patient whose AlC decreased from $16.2 \%$ at baseline while receiving glargine to $9.8 \%$ while receiving determir, and this very dramatic change in AlC skewed the data. When the data for this patient were removed, the AlC did not change from baseline (mean 9.4\%). These findings suggest that a unitfor-unit conversion from insulin glargine to insulin detemir, as suggested by the manufacturer of insulin detemir, may not be adequate. In addition to an increase in basal insulin doses, an increase in total insulin doses was also observed. The reason for the lack of improvement in AlC despite more aggressive insulin regimens is unclear.

The need for twice-daily administration was found to be more frequent with insulin detemir than with insulin glargine. This can be explained by the pharmacokinetic differences between insulin detemir and insulin glargine; insulin glargine typically has a 24-hour duration of action, whereas the duration of action of insulin detemir is dose dependent. In one study, insulin detemir's duration of action was demonstrated to vary from $5.7,12.1,19.9,22.7$, and 23.2 hours with doses of $0.1,0.2,0.4,0.8$, and 1.6 units $/ \mathrm{kg}$, respectively. ${ }^{10}$ In our study, the average insulin detemir dose at 12 months was $0.41 \mathrm{unit} / \mathrm{kg} / \mathrm{day}$ in patients with T1DM (10 patients) and 0.68 unit/ $\mathrm{kg} /$ day in patients with T2DM (21 patients). Thus, it would be expected to have durations around 20 and 21 hours, respectively. The average basal insulin dose in patients who were receiving twice-daily insulin detemir at study completion was $0.40 \mathrm{unit} / \mathrm{kg} / \mathrm{day}$ in patients with T1DM (five patients) and $0.87 \mathrm{unit} / \mathrm{kg} /$ day in patients with T2DM (10 patients) at 12 months. This could help explain the increased number of patients requiring twice-daily administration of insulin detemir, particularly in the patients with T1DM. This may also contribute to the increase in basal insulin dose when patients with T2DM were converted to insulin detemir, as it has been demonstrated in previous trials that when twicedaily administration of basal insulin is used, the basal insulin dose is often elevated without corresponding glycemic control. ${ }^{18-20}$ It should be considered that more frequent administration may also result in increased health care costs and burden to the patient and may not be desirable in all patients.

In addition, no significant weight gain or change in the frequency of hypoglycemia was observed despite the use of higher basal insulin doses in patients with T2DM. Although not statistically significant, it can be argued that the differences observed were clinically significant and may be important considerations in patients experiencing difficulties with weight gain or hypoglycemia while being treated with insulin glargine. 
Previous trials have compared insulin glargine and insulin detemir doses, primarily as a secondary end point or for a shorter study duration, and have suggested that higher insulin detemir doses may be required compared with insulin glargine to achieve similar or improved glycemic control. ${ }^{12-14,}, 17$ In one study, higher mean basal insulin doses were reported for 321 patients with T1DM with twice-daily insulin detemir compared with once-daily insulin glargine after 26 weeks ( 0.47 vs $0.35 \mathrm{unit} / \mathrm{kg} /$ day) with similar AlC reduction $(8.8 \%$ to $8.2 \%$ in the insulin detemir group and $8.7 \%$ to $8.2 \%$ in the insulin glargine group); however, no $\mathrm{p}$ value was reported for the difference between doses. ${ }^{13}$

The minimal change in basal insulin doses in patients with T1DM observed in this study is different than that observed in a previous trial in which basal insulin doses were found to increase from 36 to 46 units/day after 12 months in 24 patients with T1DM who were converted from insulin glargine to insulin detemir. ${ }^{15}$ This was compared with a control group of patients who continued to receive insulin glargine, in whom there was no change in dose. The explanation for the difference in findings between our study and this previous study is unclear, but it is possible that no difference was observed in our study because of the small number of patients with T1DM. Although no statistically significant change in AlC was noted in our study, it could be argued that a clinically relevant increase in $A l C$ was observed after the change from insulin glargine to insulin detemir, indicating that perhaps higher insulin detemir doses were warranted.

Two different studies in patients with T2DM reported a similar increase in mean basal insulin detemir dose requirements. ${ }^{12,}{ }^{14}$ Whereas one trial found no significant difference in basal insulin doses after 52 weeks in patients converted to either insulin detemir or insulin glargine (baseline AlC 8.7\%), ${ }^{17}$ another study noted an increase in mean basal insulin doses in patients with T2DM from 0.27 to 0.32 unit $/ \mathrm{kg} /$ day $(p<0.001)$ when patients were converted from once-daily insulin glargine to once- or twice-daily insulin detemir, with a subsequent decrease in AlC $(-0.59 \%, p<0.0001)$ after 12 weeks (baseline AlC 8.31\%). ${ }^{12}$ Most of the patients $(79 \%)$ in this trial were converted to once-daily insulin detemir. Another study randomized patients to either once-daily insulin glargine (248 patients) or once-daily (45\%) or twice-daily (55\%) insulin detemir (227 patients) and found higher daily insulin detemir doses of $0.78 \mathrm{unit} / \mathrm{kg}$ (0.52 unit $/ \mathrm{kg}$ with once-daily insulin detemir and $1.00 \mathrm{unit} / \mathrm{kg}$ with twice-daily insulin detemir) compared with 0.44 unit $/ \mathrm{kg}$ with insulin glargine, with similar glycemic reductions (baseline AlC decreased from 8.6\% to $7.2 \%$ and $7.1 \%$ with insulin detemir and insulin glargine, respectively). ${ }^{14} \mathrm{~A}$ pooled analysis of 22 studies of at least 20 weeks' duration in patients with T2DM initiating either insulin glargine or insulin detemir evaluated dose requirements and found that a significantly higher insulin detemir dose was needed to achieve the same decrease in AlC (51.5 vs 38.8 units/ day). ${ }^{21}$ It should be noted that only one of the trials included in this analysis was a head-tohead comparison.

The difference in dose requirements between insulin detemir and insulin glargine is further supported by a case series assessing the reverse scenario: basal insulin dose requirements in three patients with T2DM who were converted from insulin detemir to insulin glargine. ${ }^{16}$ Basal insulin doses were found to decrease substantially in all three patients, from 206 units of insulin detemir to 104 units of insulin glargine 7 weeks after conversion in the first patient, from 102 to 81 units after 6 weeks in the second patient, and from 126 to 104 units after 6 weeks in the third patient. No change or a slight improvement in $\mathrm{AlC}$ was observed on conversion to insulin glargine.

Conflicting recommendations regarding the conversion between intermediate-acting and long-acting insulin also add to the confusion. When converting from intermediate-acting NPH insulin to long-acting insulin detemir, the manufacturer states that some patients may require more insulin detemir compared with NPH insulin to achieve glycemic targets. ${ }^{8}$ This was demonstrated in a study in which the insulin detemir doses required were 1.4-4 times higher (mean 2.4) than the NPH insulin doses. ${ }^{22}$ In contrast, when patients are transferred from twice-daily NPH insulin to once-daily insulin glargine, it is recommended to reduce the initial insulin glargine dose by $20 \%$ to reduce the risk of hypoglycemia and then adjust the dose based on patient response. ${ }^{6}$ Given that higher doses of insulin detemir are generally required compared with NPH insulin and that insulin doses should be reduced when converting from NPH insulin to insulin glargine, the evidence supporting a unit-for-unit conversion from insulin glargine to insulin detemir seems inconsistent. 
There are some study limitations that should be noted. First, this was a retrospective analysis with a small patient population. Second, more than half $(63.3 \%)$ of the patients included in this study had an adjustment in their insulin glargine dose within 3 months before their documented baseline AlC. Thus, the baseline AlC may not have been a true reflection of the patients' glycemic control while receiving insulin glargine and may have actually overestimated their baseline AlC. In addition, data on drug adherence were unable to be collected given the retrospective nature of the study. Therefore, it is possible that no improvement in glycemic control was observed despite the higher prescribed insulin detemir doses due to poor adherence rates. Similarly, it should be noted that diabetes is a progressive disorder and often requires intensification of therapy the longer a patient has the disease, and there was no control group in this study for comparison. This, too, could be suggested as the reason that no AlC reduction was observed with the higher insulin detemir doses, and the lack of a control group for comparison limited our ability to assess for this. However, given that patients seemed to require higher doses even early in the follow-up period (at 1,3 , and $6 \mathrm{mo}$ ), disease progression was not thought to be the primary reason for the higher insulin detemir doses observed in patients with T2DM.

\section{Conclusion}

Treatment with insulin detemir appears to require more frequent administration and higher insulin doses compared with insulin glargine in patients with T2DM, with 33\% higher doses, on average, observed in this study. These findings suggest that a unit-for-unit conversion from insulin glargine to insulin detemir as suggested by the manufacturer of insulin detemir may not be adequate, particularly in patients with uncontrolled T2DM.

\section{References}

1. UK Prospective Diabetes Study (UKPDS-33). Intensive bloodglucose control with sulphonylureas or insulin compared with conventional treatment and risk of complications in patients with type 2 diabetes (UKPDS 33). Lancet 1998;352:837-53.

2. Diabetes Control and Complications Trial (DCCT) Research Group. The effect of intensive treatment of diabetes on the development and progression of long-term complications in insulin-dependent diabetes mellitus. $\mathrm{N}$ Engl J Med 1993;329:977-86.

3. Nathan DM, Cleary PA, Backlund JY, et al. Intensive diabetes treatment and cardiovascular disease in patients with type 1 diabetes. N Engl J Med 2005;353:2643-53.
4. Stratton IM, Alder AI, Neil HA, et al. Association of glycaemia with macrovascular and microvascular complications of type 2 diabetes (UKPDS 35): prospective observational study. BMJ 2000;321:405-12.

5. American Diabetes Association. Standards of medical care in diabetes - 2012. Diabetes Care 2012;35(1):S11-63.

6. Sanofi-Aventis. Lantus (insulin glargine) prescribing information. Bridgewater, NJ; 2007.

7. Pharmacist's Letter/Prescriber's Letter. Comparison of insulins and injectable diabetes meds. PL Detail-Document \#281107 November 2012. Available at www.PharmacistsLetter.com. Acessed December 6, 2012.

8. Novo Nordisk Inc. Levemir [insulin detemir] prescribing information. Princeton, NJ; 2005.

9. Bell DSH. Insulin therapy in diabetes mellitus: how can the currently available injectable insulins be most prudently and efficaciously utilized? Drugs 2007;67(13):1813-27.

10. Plank J, Bodenlenz M, Sinner F, et al. A double-blind, randomized, dose-response study investigating the pharmacodynamic and pharmacokinetic properties of the longacting insulin analog detemir. Diabetes Care 2005:28 (5):1107-12.

11. Drugstore.com. Levemir (detemir); Lantus (glargine). Available from www.drugstore.com. Accessed December 12, 2011.

12. Meneghini LF, Rosenberg KH, Koenen C, Merilainen MJ, Luddeke HJ. Insulin detemir improves glycaemic control with less hypoglycemia and no weight gain in patients with type 2 diabetes who were insulin naive or treated with NPH or insulin glargine: clinical practice experience from a German subgroup of the PREDICTIVE study. Diabetes Obes Metab 2007;9 (3):418-27.

13. Pieber TR, Treichel HC, Hompesch B, et al. Comparison of insulin detemir and insulin glargine in subjects with type 1 diabetes using intensive insulin therapy. Diabetes Med 2007;24:635-42.

14. Rosenstock J, Davies M, Home PD, Larsen J, Koenen C, Schernthaner G. A randomized, 52-week, treat-to-target trial comparing insulin detemir with insulin glargine when administered as add-on to glucose-lowering drugs in insulin-naive people with type 2 diabetes. Diabetologia 2008;51:408-16.

15. Kabadi U. Deleterious outcomes after abrupt transition from insulin glargine to insulin detemir in patients with type 1 diabetes mellitus. Clin Drug Invest 2008;28(11):697-701.

16. Swinnen SGHA, Hans DeVries J. Higher dose requirements with insulin detemir in type 2 diabetes - three cases and a review of the literature. Diabetes Res Clin Pract 2009;84:e246.

17. Hollander P, Cooper J, Bregnhj J, Pedersen CB. A 52-week, multinational, open-label, parallel-group, noninferiority, treat-to-target trial comparing insulin detemir with insulin glargine in a basal-bolus regimen with mealtime insulin aspart in patients with type 2 diabetes. Clin Ther 2008;30:1976-87.

18. DeVries JH, Nattrass M, Pieber TR. Refining basal insulin therapy: what have we learned in the age of analogues? Diab Metab Res Rev 2007;23:441-54.

19. Albright ES, Desmond R, Bell DS. Efficacy of conversion from bedtime NPH insulin injection to once- or twice-daily injections of insulin glargine in type 1 diabetic patients using basal/ bolus therapy. Diabetes Care 2004;27:632-3.

20. Ashwell SG, Gebbie J, Home PD. Twice-daily compared with once-daily insulin glargine in people with type 1 diabetes using meal-time insulin aspart. Diabetes Med 2006;23:879-86.

21. Daily G, Admane K, Mercier F, Owens D. Relationship of insulin dose, Alc lowering, and weight in type 2 diabetes: comparing insulin glargine and insulin detemir. Diabetes Technol Ther 2010;12(12):1019-27.

22. Hermansen K, Madsbad S, Perrild H, Kristensen A, Axelsen M. Comparison of the soluble basal insulin analog insulin detemir with NPH insulin: a randomized open crossover trial in type 1 diabetic subjects on basal-bolus therapy. Diabetes Care 2001;24(2):296-301. 